\title{
Modelling and analysis of grid-connected solar-PV system through current-mode controlled VSC
}

\author{
Elsayed Saad, Yasser Elkoteshy, and Usama AbouZayed \\ Electrical Power and Energy, Military Technical College, Cairo, Egypt
}

\begin{abstract}
Recently, solar-PV energy becomes one of the most vital renewable resources of electrical energy as it is utilized in all life applications. In case of connecting the solar-PV system with the utility grid a voltage-sourced converter (VSC) is required to convert the extracted solar-PV array's DC power into AC. There are many methods to dominate the active and reactive power produced from the VSC. In the following model we use the current mode control as it has some features such as highly output accuracy, protection against over current troubles, robustness against AC side voltage and load variations. As the produced power from the solar cells is intermittent, the point of maximum power has to be tracked using an MPPT technique. Also, in order to reduce the system harmonics a filter must be implemented in the model. In this paper, a complete model of 50KW grid-connected solar-PV system using current-mode controlled two-level three-phase VSC (grid imposed frequency VSC) is implemented. Also, the Incremental Conductance model to track the point of maximum available power (MPPT) and LCL filter has been provided into the system with total harmonic distortion (THD) analysis in PSCAD/EMTDC
\end{abstract}

\section{Introduction}

The growing consumption of electrical energy in all aspects of life forced the world to search and discover renewable resources of energy to compensate the insufficiency of the required energy. One of the most vital resources of energy is the solar-PV as it is clean, available, sustainable, renewable and has no maintenance cost. Solar-PV output power is intermittent since it depends on solar irradiance and ambient temperature. Therefore, maximum power point tracking techniques (MPPT) have been utilized in the PV systems to ensure the extraction of maximum available power at any environmental conditions. There are many techniques to determine the point of maximum power such as Perturb\& Observe, Hill Climbing, Neural Network and the Incremental Conductance method which is implemented in this model.

In this paper, a switched model of two-level threephase VSC is used to mutate the solar-PV cell's DC power into AC power to match with the grid power. As the VSC inject harmonics in the system due to switching, LCL filter is designed and inserted into the system[1]. Grid-imposed frequency VSC system using currentcontrol mode is executed to hold the instantaneous active and reactive power that transmitted from the inverter to the utility [2]. This mode of control protects the VSC in case of over-current conditions, so it is more preferable

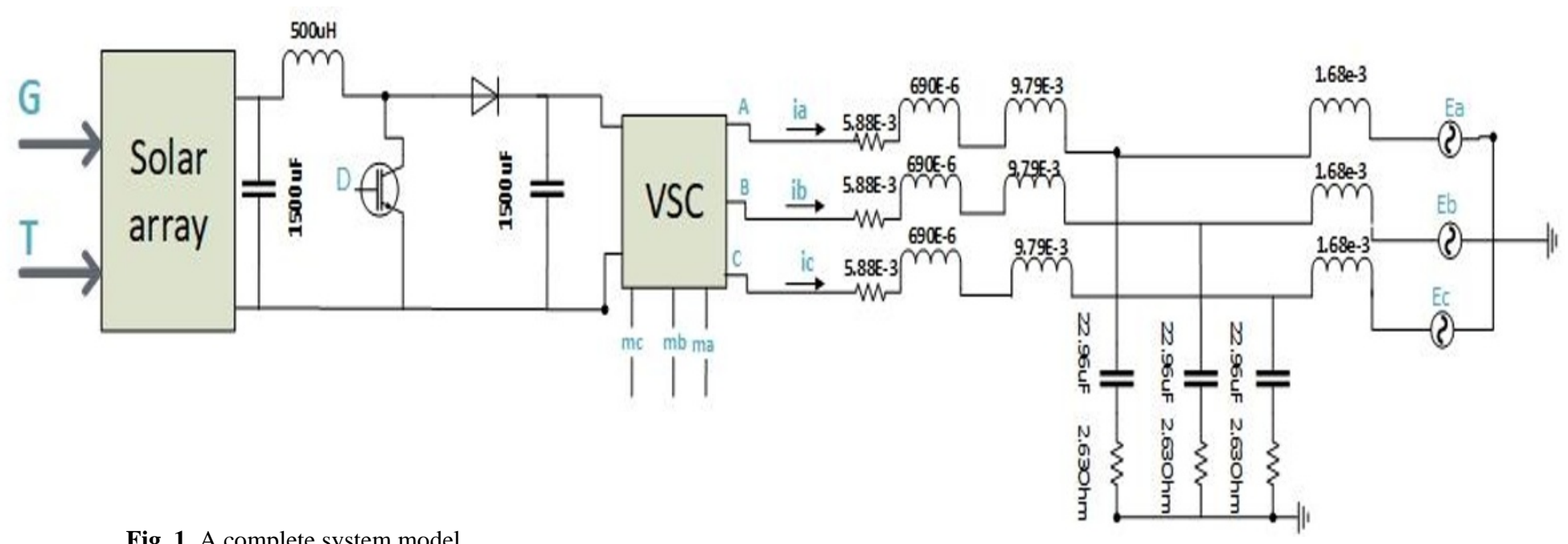

Fig. 1. A complete system model 
than the voltage-control mode. In Fig.1 a complete model of $50 \mathrm{KW}$ grid-connected solar-PV system in PSCAD/ EMTDC is presented.

This paper presents an overview study of gridconnected solar-PV system through current-mode controlled VSC with Incremental Conductance method to track the MPP and an LCL filter to minimize the generated harmonics impact with total harmonic distortion analysis.

\section{Solar photo-voltaic panel's model}

Photo-voltaic (PV) effect is the process of conversion the solar radiation into electrical energy $[3,4]$. The solar-PV array consists of a group of PV-panels each of them contains a number of series and parallel-connected PV cells. The type of connection depends on the desired voltage and current levels at which the required power will be produced.

To study the characteristics of the solar-PV cell, its generally equivalent circuit is presented in Fig. 2 where:

The current source $\mathrm{I}_{\mathrm{L}}$ represents the produced photocurrent from the sun radiation and the resistances $R_{P}, R_{S}$ represent the current leakage and the semiconductor losses respectively.In this paper, the implemented model for a PV-solar cell depends on the following equations:

$$
\begin{gathered}
I_{C}=I_{L}-I_{d}-I_{P} \\
I_{L}=I_{s c R} *\left(G / G_{\text {nom }}\right)\left[1+\alpha\left(T-T_{n o m}\right)\right] \\
I_{d}=I_{o}\left[\exp \left\{q\left(V_{c}+I_{c} R_{s}\right) / n K T\right\}-1\right] \\
I_{o}=I_{o R} *\left(\left(T / T_{\text {nom }}\right)^{3}\right) *\left\{\exp \left[\left(\left(1 / T_{\text {nom }}\right)-(1 / T)\right) *\left(q E_{g} / n k\right)\right]\right\} \\
I_{P}=\left(V_{c}+I_{c} R_{s}\right) / R_{p}
\end{gathered}
$$

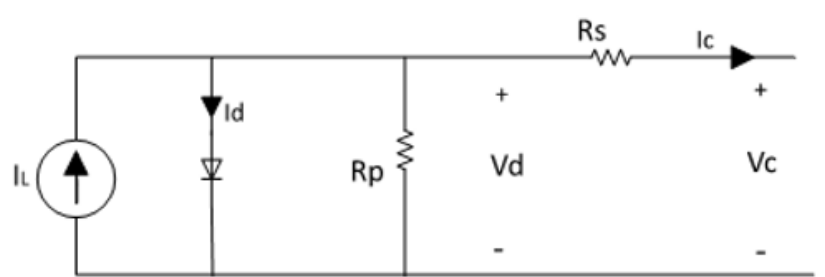

Fig. 2. Solar cell equivalent circuit.

Where Iscr is the short circuit current at nominal radiation, $\mathbf{G}$ is the radiation level in $\left(\mathrm{W} / \mathrm{m}^{2}\right), \mathbf{G}$ nom is the radiation level at standard test conditions that $\left(\mathrm{G}_{\mathrm{STC}}=\right.$ $\left.1000 \mathrm{~W} / \mathrm{m}^{2}\right), \boldsymbol{\alpha}$ is the light generated current co-efficient temperature, $\mathbf{T}$ is the measured cell temperature, $\mathbf{T}_{\text {nom }}$ is the normal standard test conditions cell temperature that $\left(\mathrm{T}_{\mathrm{STC}}=25^{\circ} \mathrm{C}\right), \mathbf{V}_{\mathbf{C}}$ and $\mathbf{I}_{\mathbf{C}}$ are the solar-PV cell outputs voltage and current and $\mathbf{n}$ is the emission constant of the diode. This model is valid for any PV system under different output power ratings and operating conditions. To gene-rate the $50 \mathrm{KW}$ required output power at STC, 16x7 series-parallel connected modules with each one contains 108 series and 4 parallel cells. Also, the other parameters are chosen to be as the following:

$\mathbf{G}_{\mathbf{n o m}}=1000 \mathrm{~W} / \mathrm{m}^{2}, \mathbf{T}_{\mathbf{n o m}}=25^{\circ} \mathrm{C}, \mathbf{R}_{\mathbf{s}}=0.02 \Omega, \quad \mathbf{R}_{\mathbf{P}}=1000 \Omega$, $\mathbf{n}=1.5, \mathbf{I S C R}_{\mathbf{S C R}}=2.5 \mathrm{~A}, \boldsymbol{\alpha}=0.001 \mathrm{~A} / \mathrm{K}$
Fig. 3 shows the solar-PV model's output voltage, current and power, depending on the previous equations and default values.

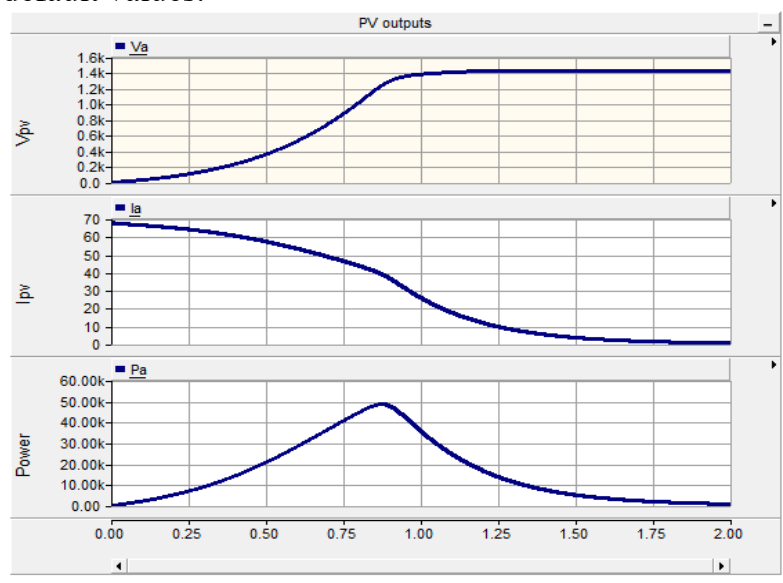

Fig. 3. PV model outputs.

The performance of a solar-PV cell and its output power are fundamentally relay on the solar radiation intensity and temperature [5]. The environmental variations of the sun have a magnificent impact on the extracted power. When the cell temperature increases the output voltage decreases as shown in Fig.4 (where the temperature varies from $20^{\circ} \mathrm{C}$ to $80^{\circ} \mathrm{C}$ with step $15^{\circ} \mathrm{C}$ ). The output cell current increases when the radiation level increases as shown in and Fig.5 (where the irradiation increases from $200 \mathrm{~W} / \mathrm{m}^{2}$ to $1000 \mathrm{~W} / \mathrm{m}^{2}$ with step $200 \mathrm{~W} / \mathrm{m}^{2}$ ).

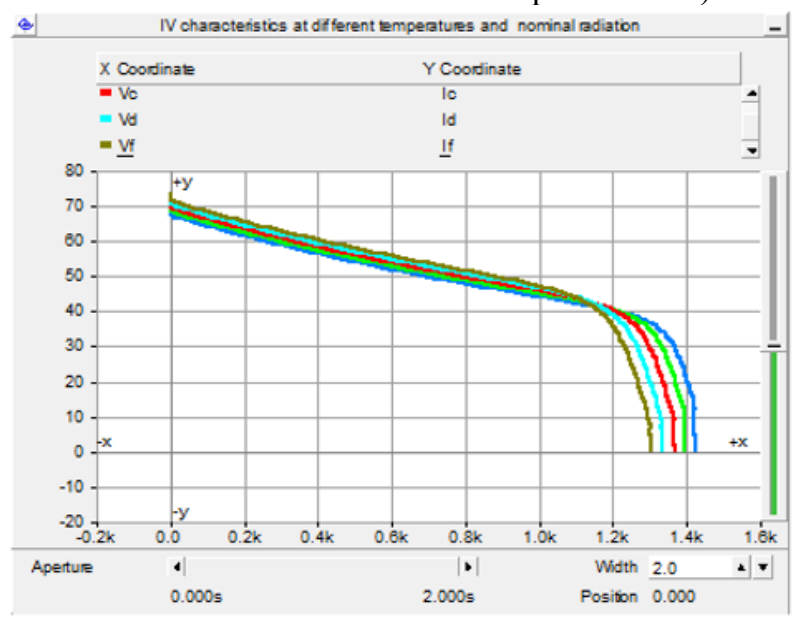

Fig.4. IV characteristics at different temperatures and nominal radiation.

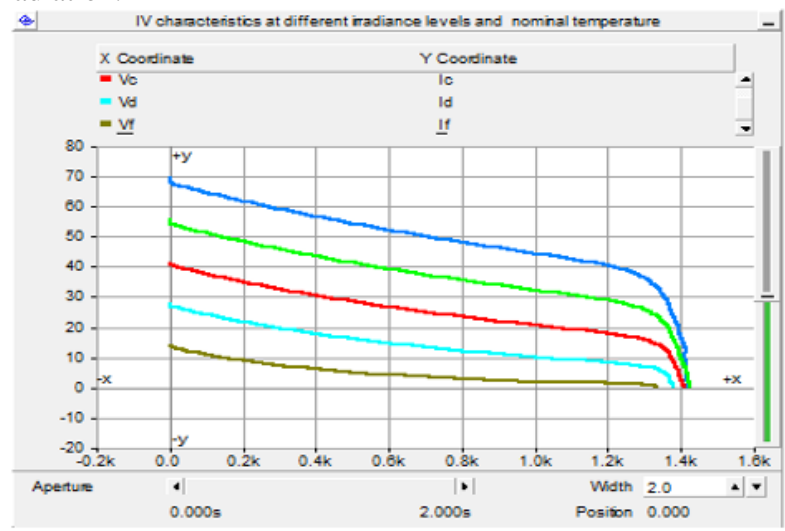

Fig. 5. IV characteristics at different irradiance levels and nominal temperature. 


\section{MPPT modelling}

Since the MPP position changes with the variation of solar irradiance and cell temperature, abundant techniques to track the extracted maximum power from the solar cell have been developed and implemented[6-8]. Boost converter plays a vital role in MPPT model as it has the ability of self adjusting its duty cycle depending on the position of MPP[5]. Its duty cycle can be calculated as in the following equations [9]:

$$
\begin{gathered}
D=1-\left(V_{m p p} / V_{o}\right)-\Delta D \\
\Delta D=K^{*}\left(V_{m p p}-V_{p v}\right)
\end{gathered}
$$

Where: $\mathbf{V}_{\mathbf{m p p}}$ is the MPP voltage, $\mathbf{V}_{\mathbf{o}}$ is the boost output voltage, $\mathbf{V}_{\mathbf{p v}}$ is the PV voltage, $\mathbf{K}$ is a positive constant and $\mathbf{\Delta} \mathbf{D}$ is the duty cycle disturbance that helps in reaching the MPP position quickly. In this model, the incremental conductance technique is implemented depending on its mentioned algorithm in[5]. This technique is relay on the slope of the curve which represents the relation between the output power and voltage of the solarPV model , such that the slope $=(\mathbf{d P} / \mathbf{d V})$ as follows [6]:

- Slope $=0$ (MPP is reached)

- Slope $<0$ (at the right of MPP)

- Slope $>0$ (at the left of MPP)

By using derivative then:

$$
\begin{aligned}
\text { Slope } & =(\mathrm{dP} / \mathrm{dV})=(\mathrm{d}(\mathrm{IV}) /(\mathrm{dV}))=\mathrm{I}+\mathrm{V}(\Delta \mathrm{I} / \Delta \mathrm{V}) \\
& =(\mathrm{I} / \mathrm{V})+(\Delta \mathrm{I} / \Delta \mathrm{V})
\end{aligned}
$$

So, the MPP can be achieved by measuring the instantaneous and the incremental conductance $\{(\mathrm{I} / \mathrm{V})$ and $(\Delta \mathrm{I} / \Delta \mathrm{V})$ respectively $\}$ then comparing these values to determine the sign of the slope, the direction of curve sweeping and hence the value of VPV will be decrement or increment depending on the MPP position. The tracking of MPP at different environmental conditions (radiation changes from $1000 \mathrm{~W} / \mathrm{m}^{2}$ to $700 \mathrm{~W} / \mathrm{m}^{2}$ and temperature changes from $25^{\circ} \mathrm{C}$ to $40^{\circ} \mathrm{C}$ ) is shown in Fig. 6 .

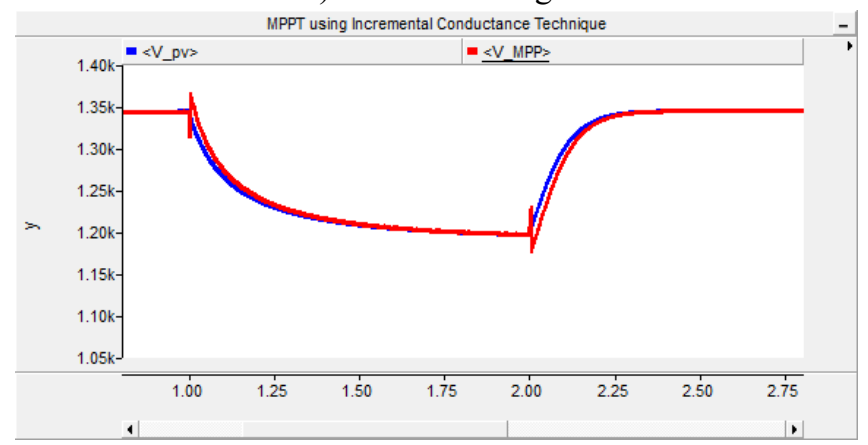

Fig. 6. MPPT using Incremental Conductance Technique.

\section{Three-phase VSC model}

In this model, the main function of the three-phase VSC (inverter) is to transform the boost converter DC output power into $\mathrm{AC}$ power to be suitable for the connection with the utility grid. The gating signals are generated based on sinusoidal pulse width modulation (SPWM) technique by comparing a sinusoidal modulating signals (generated by the closed-loop control scheme of the VSC) with a triangular carrier wave with high switching frequency [1]. The VSC's control loops are implemented to hold the active and reactive power that generated from it and transmit to the utility grid. This controller can be done depending on current control mode or voltage control mode[2]. Although, the voltage control mode is simple in implementation, it has no control on the VSC line current and no protection against over current troubles. However the current mode control is complicated, it has some features such as highly output accuracy, protecttion against over current troubles, robustness against AC side voltage and load variations[10]. The control is produced in dq-frame as shown in Fig.7, so the AC signals must be converted from abc-frame to dq-frame using the following Clark transformation matrix[11].

$$
\left(\begin{array}{l}
d \\
q \\
0
\end{array}\right)=\frac{2}{3}\left(\begin{array}{ccc}
\cos \theta & \cos \left(\theta-\frac{2 \pi}{3}\right) & \cos \left(\theta+\frac{2 \pi}{3}\right) \\
\sin \theta & \sin \left(\theta-\frac{2 \pi}{3}\right) & \sin \left(\theta+\frac{2 \pi}{3}\right) \\
\frac{1}{2} & \frac{1}{2} & \frac{1}{2}
\end{array}\right)\left(\begin{array}{l}
a \\
b \\
c
\end{array}\right)
$$

The control loop consists of the following components:

\subsection{Phase-locked loop}

The transformation from the abc-frame to dq-frame requires synchronization between the abc values and the dq values thus, phase-locked loop (PLL) block must be inserted into the system. Basically, it consists of voltage controlled oscillator ( $\mathrm{VCO}$ ), limiter to the output signal and compensator. The produced transformation angle $(\theta$ in radians) from the PLL and the dq values of AC voltage are shown in Fig. 8 where $\theta=6.28[\mathrm{rad}] \cong 360 \mathrm{o}, \mathrm{V}_{\mathrm{sd}}=391 \mathrm{v}$ and $\mathrm{V}_{\mathrm{sq}}=0$

\subsection{Reference signal generator}

It's main function is to match the system produced real and reactive power with their required values and also to produce the reference values of current in dq-frame ( $\left.i_{\text {dref }}\right),\left(i_{\text {qref }}\right)$ depending on the following equations:

$$
\begin{aligned}
& i_{\text {dref }}(t)=\left(2 / 3 V_{\text {sd }}\right) P_{\text {sref }}(t) \\
& i_{\text {qref }}(t)=\left(-2 / 3 V_{\text {sd }}\right) Q_{\text {sref }}(t)
\end{aligned}
$$

\subsection{Compensator}

The compensator is used to regulate the value of the controlling signal $\mathrm{md}$, mq. Its inputs are $\left(\mathrm{i}_{\text {dref }}\right)$, ( $\left.\mathrm{i}_{\mathrm{qref}}\right)$, $\left(\mathrm{V}_{\mathrm{sd}}\right),\left(\mathrm{V}_{\mathrm{sq}}\right),\left(\mathrm{i}_{\mathrm{d}}\right),\left(\mathrm{i}_{\mathrm{q}}\right),\left(\mathrm{V}_{\mathrm{PV}}\right)$ and its outputs are $\left(\mathrm{m}_{\mathrm{d}}\right)$, $\left(\mathrm{m}_{\mathrm{q}}\right)$. The following equations represent its operation:

$$
\begin{aligned}
& m_{q}=\left[\left\{\left(i_{\text {qref }}-i_{q}\right) * k_{q}+L W i_{d}+V_{s q}\right\} / V_{p v_{-} \text {half }}\right] \\
& m_{d}=\left[\left\{\left(i_{\text {dref }}-i_{d}\right) * k_{d}+L W i_{q}+V_{s d}\right\} / V_{p v_{-} \text {half }}\right]
\end{aligned}
$$

These signals must be converted again from dq-frame to abc-frame, thus the switching signals of the VSC has been produced. 


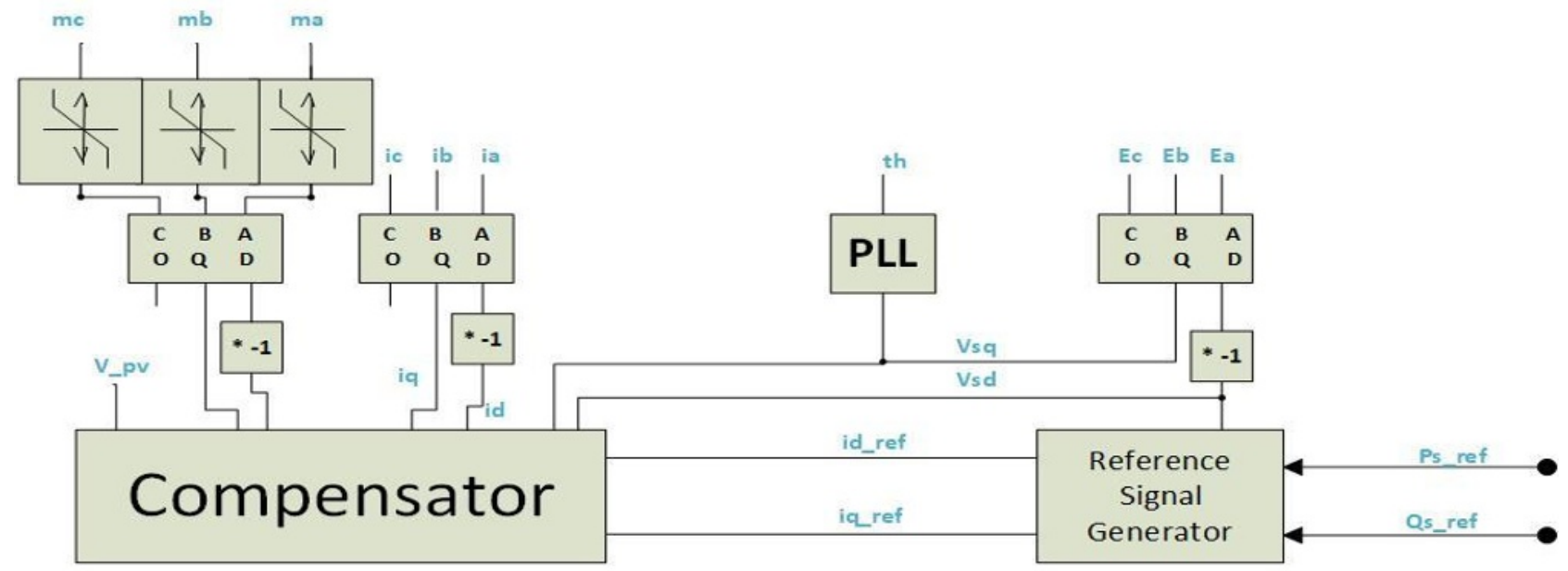

Fig. 7. VSC control model.

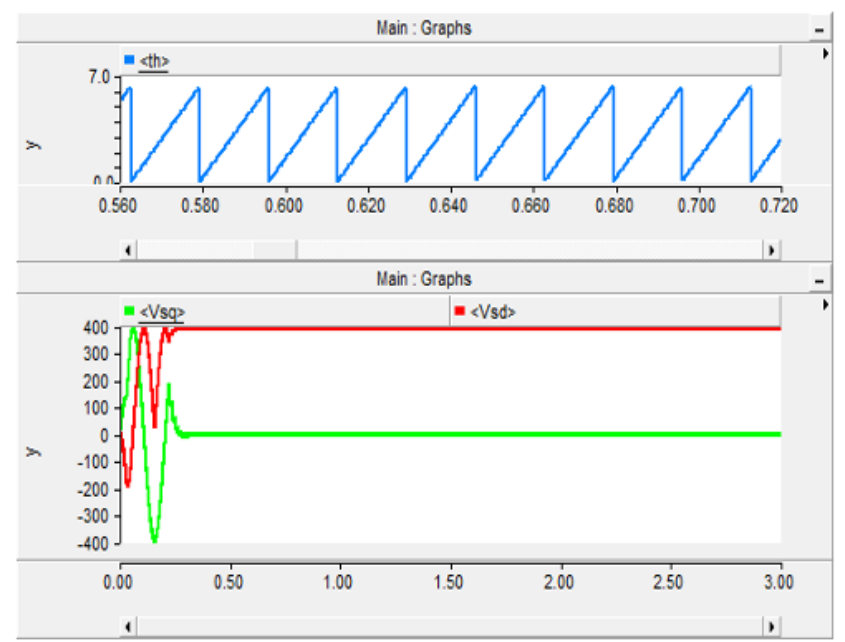

Fig. 8. PLL response.

\section{LCL filter modelling}

The VSC switches inject harmonics into the system[1]. In order to reduce their effect on the generated current and voltage, passive filters such as LCL filter is designed and inserted into the system between the grid and the inverter. The designing procedures of the LCL filter are introduced in[12]. Depending on these designing steps the LCL filter parameters would be:

- $\mathrm{L}_{1}=9.79 \mathrm{mH}$ (inverter side inductance)

- $\mathrm{L}_{2}=1.68 \mathrm{mH}$ (grid side inductance)

- $\mathrm{C}_{\mathrm{f}}=22.96 \mu F$ (filter capacitor)

- $\mathrm{R}_{\mathrm{f}}=2.63 \Omega \quad$ (damping resistance)

\section{Total harmonic distortion analysis}

The existence of harmonics causes power quality problems. The three-phase VSC output currents with and without using LCL filter at point of common coupling (PCC) is shown in Fig.9 and Fig.10, respectively. The THD measure of the current or voltage at PCC gives indication about the amount of harmonics in the system. To maintain the power quality within acceptable limits, standards such as IEEE Std 929-2000 [13] and IEEE Std 519-1992[14] have been produced. Referring to these standards the THD of the current at the point of common coupling (PCC) shouldn't exceed 5\% of the fundamental. Fig. 11 and Fig.12 show the total and individual harmonic distortion (THD, IHD) percentages of the utility currents at PCC after and before connecting the LCL filter, respectively. It's obvious that the THD and IHD decreased after using the LCL filter.

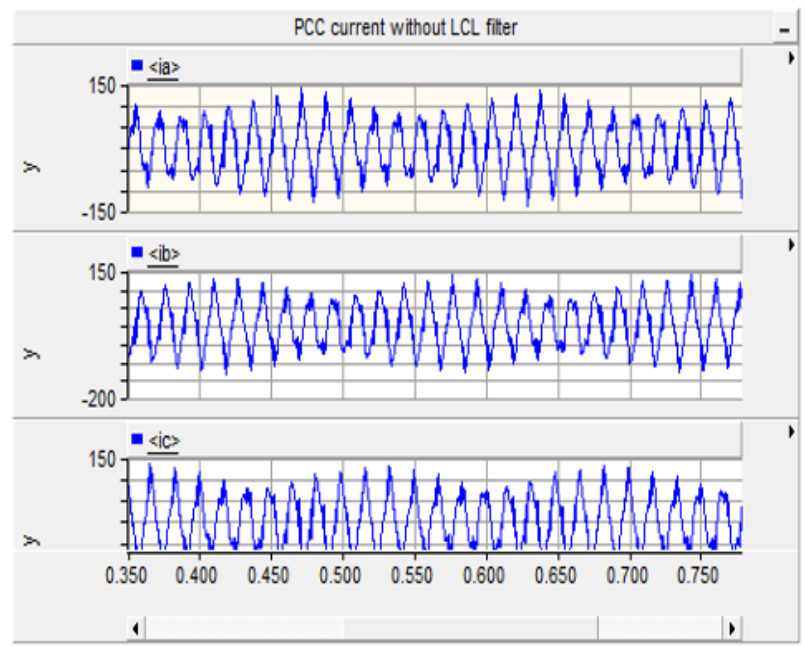

Fig. 9. Three phase VSC output currents without using LCL filter.

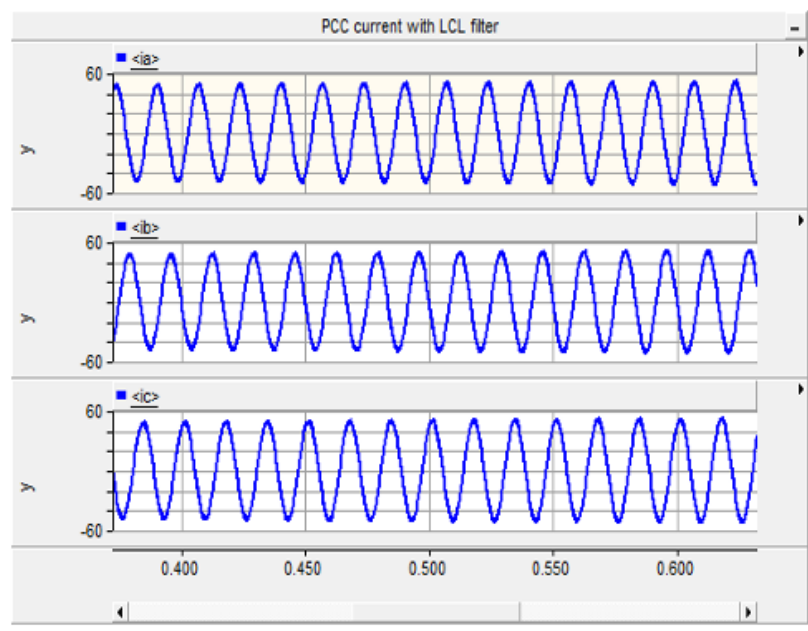

Fig. 10. Three phase VSC output currents after using LCL filter. 


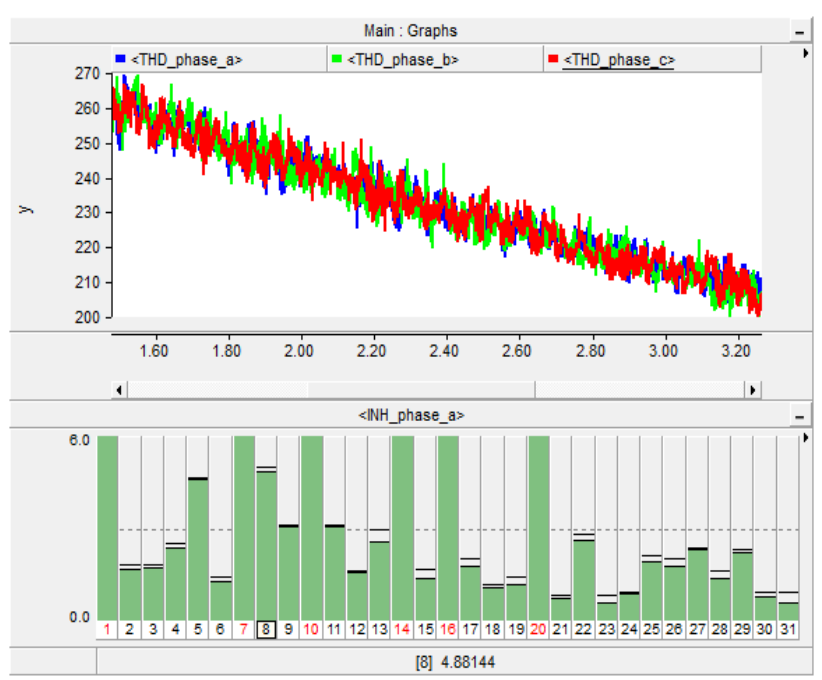

Fig. 11. THD of phase a,b,c and IHD of phase a for the utility currents at PCC without LCL filter.

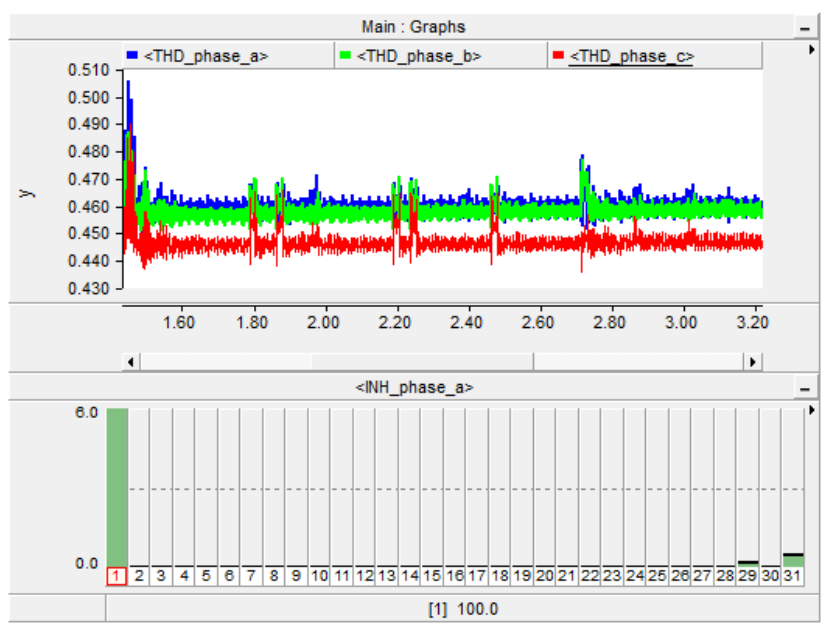

Fig. 12. THD of phase a,b,c and IHD of phase a for the utility currents at PCC after using LCL filter.

\section{Conclusion}

The main contribution of this paper is that grid-connected PV system has been modeled and investigated using PSCAD/EMTDC with current control mode to dominate the real and reactive power that transmitted from the VSC to the grid. MPPT is implemented in the system relay on the Incremental Conductance algorithm. Also, to minimize the generated harmonics impact on the system outputs, an LCL filter is implemented. Finally the total harmonic distortion (THD) at PCC is analyzed.

The authors of this publication would like to express their most profound and sincere appreciation to Dr. Sherif Helmy for his supervision, guidance, generous advice, criticism and continuous support throughout this research.

\section{References}

1. M. H. Rashid, Power electronics handbook: Butterworth-Heinemann, (2017).

2. A. Yazdani and R. Iravani, Voltage-sourced converters in power systems: modeling, control, and applications: John Wiley \& Sons, (2010).

3. X. Deng, E. A. Schiff, A. Luque, and S. Hegedus, "Handbook of photovoltaic science and engineering," A. Luque, John Wiley \& Sons, Chichester, (2003).

4. B. Zaidi, "Introductory Chapter: Introduction to Photovoltaic Effect," Solar Panels and Photovoltaic Materials; InTech Open: London, UK, pp. 1-8, (2018).

5. N. Femia, G. Petrone, G. Spagnuolo, and M. Vitelli, Power electronics and control techniques for maximum energy harvesting in photovoltaic systems: CRC press, (2012).

6. T. Esram and P. L. Chapman, "Comparison of photovoltaic array maximum power point tracking techniques," IEEE Transactions on energy conversion, vol. 22, pp. 439-449, (2007).

7. A. R. Reisi, M. H. Moradi, and S. Jamasb, "Classification and comparison of maximum power point tracking techniques for photovoltaic system: A review," Renewable and sustainable energy reviews, vol. 19, pp. 433-443, (2013).

8. B. Subudhi and R. Pradhan, "A comparative study on maximum power point tracking techniques for photovoltaic power systems," IEEE Transactions on sustainable energy, vol. 4, pp. 89-98, (2012).

9. H. Patel and V. Agarwal, "Maximum power point tracking scheme for PV systems operating under partially shaded conditions," IEEE transactions on industrial electronics, vol. 55, pp. 1689-1698, (2008).

10. M. P. Kazmierkowski and L. Malesani, "Current control techniques for three-phase voltage-source PWM converters: A survey," IEEE transactions on industrial electronics, vol. 45, pp. 691-703.

11. P. Klause, O. Wesynczuk, and S. Sudhoff, "Analysis of Electric Machinary and Drive System," John Willey and Sons, Inc. Publication, (2002).

12. A. Reznik, M. G. Simões, A. Al-Durra, and S. Muyeen, "\$ LCL \$ filter design and performance analysis for grid-interconnected systems," IEEE Transactions on industry applications, vol. 50, pp. 1225-1232, (2013).

13. IEEE, IEEE recommended practice for utility interface of photovoltaic $(P V)$ systems: IEEE, (2000).

14. I. F II, "IEEE recommended practices and requirements for harmonic control in electrical power systems," New York, NY, USA, (1993). 